\title{
Nanoscale
}

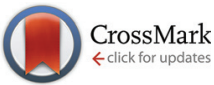

Cite this: Nanoscale, 2016, 8, 8160

\section{Phase selective synthesis of quantum cutting nanophosphors and the observation of a spontaneous room temperature phase transition $\uparrow$}

\begin{abstract}
Pushpal Ghosh*a and Anja-Verena Mudring* $\star^{\mathrm{b}, \mathrm{c}}$
Oxygen-free $\mathrm{Eu}^{3+}$-doped $\mathrm{NaGdF}_{4}$ nanocrystals with high quantum cutting efficiency are accessible at low temperatures (room temperature to $80^{\circ} \mathrm{C}$ ) using task-specific ionic liquids (ILs) as structure directing agents and only water as solvent. Selective tuning of the shape, morphology and, most importantly, the crystal phase of the host lattice is achieved by changing the alkyl side length, the $\mathrm{H}$-bonding capabilities and the concentration of 1-alkyl-3-methylimidazolium bromide ILs, $\left[C_{n}\right.$ mim] Br. When using $\left[C_{2}\right.$ mim] $B r$, hexagonal $\mathrm{NaGdF}_{4}$ nanoparticles are obtained. In the case of methylimidazolium bromides with longer pendant alkyl chains such as butyl $\left(C_{4}\right)$, octyl $\left(C_{8}\right)$ or decyl $\left(C_{10}\right)$, extremely small nanoparticles of the cubic polymorph form, which then convert even at room temperature (RT) to the thermodynamically favored hexagonal modification. To the best of our knowledge, this kind of spontaneous phase transition is not yet reported. The hexagonal nanomaterial shows a substantial quantum cutting efficiency (154\%) whilst in the cubic material, the effect is negligible (107\%). The easy yet highly phase selective green synthesis of the materials promises large scale industrial application in environmentally benign energy efficient lighting.
\end{abstract}

Received 8th January 2016

Accepted 17th March 2016

DOI: 10.1039/c6nr00172f

www.rsc.org/nanoscale achieved by a two-photon down-conversion process based on a combination of two different rare earth ions, i.e. $\mathrm{Gd}^{3+}$ and $\mathrm{Eu}^{3+}$ in $\mathrm{NaGdF}_{4}: \mathrm{Eu}^{3+}$, where the excitation energy is transferred via a two-step process from the quantum cutter $\left(\mathrm{Gd}^{3+}\right)$ to the emitting ion $\left(\mathrm{Eu}^{3+}\right)$, resulting in the emission of two visible photons. ${ }^{1,3}$ Indeed, ternary lanthanide fluorides like $\mathrm{NaGdF}_{4}$ are amongst the most effective optical materials and they are used widely in photonics and biophotonics, because of their high refractive index, low phonon energy and good stability. ${ }^{3-6}$ Various synthesis routes to nanofluorides are already explored, but, in the context of quantum cutting, special care must be taken to obtain absolutely oxide-free materials, as oxygen impurities can lead to non-radiative relaxation via europiumoxygen charge transfer states, followed by emission from these levels. ${ }^{40}$ In this context the application of ILs has been shown to be beneficial. ${ }^{31-37}$ Ionic liquids are often described as green and designer solvents, and draw currently considerable attention both in academia and industries. ${ }^{31-39}$ As ILs are composed of distinct cations and anions, they are a widely tunable class of compounds with interesting properties. Useful properties like negligible vapor pressure, wide liquidus range, good thermal stabilities, considerable electrical conductivities and a wide electrochemical window make them suitable for use in organic catalysis, electrochemistry, f-element separation and many other applications. ${ }^{31-40}$ Despite their versatility, their use in inorganic materials synthesis has just begun but holds great promises. ${ }^{41-56}$ ILs offer an advantage in the 
synthesis of inorganic nanomaterials as they can efficiently stabilize nanoparticles and shield them against agglomeration on the basis of their size and their charge. ${ }^{32,56}$ In addition, their ability to interact with the nanoparticle surface allows for morphology and also phase control. ${ }^{56}$ ILs can not only be used as a solvent but also as a reaction partner which enabled us to synthesize the first highly efficient quantum cutting, smallsized nanofluorides, $\mathrm{GdF}_{3}: \mathrm{Eu}^{3+}{ }^{57}$

Here, we present an easy yet highly phase selective synthesis of oxygen-free $\mathrm{Eu}^{3+}$-doped $\mathrm{NaGdF}_{4}$ nanocrystals (particle size below $10 \mathrm{~nm}$ ) with high quantum cutting efficiency. The synthesis only requires stirring an aqueous solution of the starting materials and a task-specific IL such as $\left[\mathrm{C}_{2} \mathrm{mim}\right] \mathrm{Br}$ (1-ethyl-3-methylimidazolium bromide) for one hour at room temperature. This synthesis protocol not only meets with the requirements of green chemistry as proposed by Anastas and Warner $^{58}$ but also offers the possibility of easy scale-up for industrial manufacturing. Tuning of the crystal phase of $\mathrm{NaGdF}_{4}$ can be achieved even at room temperature by judiciously choosing the IL. The extremely small, less thermodynamically stable nanoparticles of $\mathrm{NaGdF}_{4}$ convert at room temperature without applying external stimuli like heating to the thermodynamically more stable hexagonal phase which also has a higher quantum efficiency. Normally phase transition of nanomaterials needs at least one of the following changes: heating at high calcination temperatures, change of the reactant ratio and other external influences etc. ${ }^{59-62}$ But in the present case, spontaneous phase transition over time without using any external force is not only new and novel for sodium ternary fluoride but also very rare for other systems.

\section{Experimental}

\subsection{Synthesis of ionic liquids}

Details of the synthesis of ionic liquids used in this work are given in the ESI (Scheme $\mathrm{S} 1 \dagger$ ).

\subsection{Synthesis of $\mathrm{NaGdF}_{4}: \mathrm{Eu}^{3+}$ nanocrystals}

In a novel approach, $\mathrm{NaGdF}_{4}: \mathrm{Eu}$ nanocrystals are prepared using imidazoilium-based ILs with tunable alkyl chain length, reaction temperature etc. The synthesis only requires water as solvent and the ILs act as a nanosynthetic template. When 1-ethyl-3-methylimidazolium bromide $\left[\mathrm{C}_{2} \mathrm{mim}\right] \mathrm{Br}$ is used at room temperature, hexagonal modification appears but at higher reaction temperature $\left(80{ }^{\circ} \mathrm{C}\right)$, cubic nanorods are obtained. But on using ionic liquid of a higher chain length such as $\left[\mathrm{C}_{n} \operatorname{mim}\right] \mathrm{Br}(n=4,8,10)$ at room temperature, very small sized $(\sim 1.5 \mathrm{~nm})$ cubic nanomaterials were obtained which undergo spontaneous phase transition over time to hexagonal (general scheme in Fig. 1a).

In a typical synthesis, $0.113 \mathrm{~g} \mathrm{NaCl}$ (J. T. Baker), $0.88 \mathrm{~g}$ $\mathrm{Gd}\left(\mathrm{NO}_{3}\right)_{3} \cdot 6 \mathrm{H}_{2} \mathrm{O}$ (Alfa Aesar) and the required amount of $\mathrm{Eu}\left(\mathrm{NO}_{3}\right)_{3} \cdot 6 \mathrm{H}_{2} \mathrm{O}$ (Alfa Aesar) was added at RT to $12.5 \mathrm{~mL}$ of an aqueous solution of the respective ionic liquid (IL) with the desired concentration. To the well-stirred solution, $12.5 \mathrm{~mL}$ aqueous $\mathrm{NH}_{4} \mathrm{~F}$ (Sigma Aldrich) solution was added keeping the $\mathrm{Gd}^{3+} / \mathrm{F}^{-}$ratio at $1: 8$ in all cases. The reaction mixture was stirred at RT for 1 hour and the obtained nanocrystals were collected by centrifugation, washed several times with methanol, ethanol and acetone and dried in an oven at $80{ }^{\circ} \mathrm{C}$. In another experiment, $0.113 \mathrm{~g} \mathrm{NaCl}, 0.88 \mathrm{~g} \mathrm{Gd}\left(\mathrm{NO}_{3}\right)_{3} \cdot 6 \mathrm{H}_{2} \mathrm{O}$ and the required amount of $\mathrm{Eu}\left(\mathrm{NO}_{3}\right)_{3} \cdot 6 \mathrm{H}_{2} \mathrm{O}$ was added to $12.5 \mathrm{~mL}$ $\left(0.1 \mathrm{~mol} \mathrm{~L}^{-1}\right)$ aqueous solution of $\left[\mathrm{C}_{2} \mathrm{mim}\right] \mathrm{Br}$ at $80{ }^{\circ} \mathrm{C}$ followed by addition of $12.5 \mathrm{~mL}$ aqueous $\mathrm{NH}_{4} \mathrm{~F}$ solution. After 1 hour of constant stirring of the reaction mixture at $80^{\circ} \mathrm{C}$, the obtained nanocrystals are centrifuged, washed and collected as described.

\subsection{Characterization}

PXRD (powder X-ray diffraction) measurements were carried out on a Huber G70 diffractometer (Rimsting, Germany) using Mo $\mathrm{K} \alpha$ radiation $(\lambda=0.07107 \mathrm{~nm})$. The crystallite size was calculated using the Scherrer equation, $D=K \lambda / \beta \cos \theta$, where $K=$ $0.9, D$ represents the crystallite size $(\AA), \lambda$ is the wavelength of Mo $\mathrm{K} \alpha$ radiation, and $\beta$ is the corrected half width of the diffraction peak. TEM (transmission electron microscopy; FEI Tecnai F20 field emission gun TEM, Philips Electron Optics, Holland) was used to map the shape, size and lattice structure of the nanocrystals dispersed on a carbon-coated copper grid from acetone solution. Morphological characterization was also carried out by a JEOL, JSM-6700F FESEM (Japan). The excitation and emission spectra and decay time of all samples were recorded on a Fluorolog 3 (HORIBA JOBIN YVON, Germany) luminescence spectrometer equipped with steady and pulsed Xe lamps for sample excitation and a photomultiplier for signal detection. All measurements were performed at room and liquid nitrogen temperature. Excitation and emission spectra using high energy synchrotron radiation were taken at beamline I (SUPERLUMI) of the Doris III storage ring at HASYLAB, Deutsches Elektronen Synchrotron (DESY) in Hamburg, Germany. ${ }^{63}{ }^{1} \mathrm{H}$ NMR was measured on a Bruker DPX-200 (200 MHz) (Karlsruhe, Deutschland).

\section{Results and discussion}

\subsection{Structural characterizations by powder X-ray diffraction and phase evolution}

The phase evolution using various task-specific ILs and transformation is depicted schematically by Fig. 1a.

3.1.1 Effect of the aromatic $\pi$-system of the IL on phase evolution. Pure hexagonal $\mathrm{NaGdF}_{4}$ is obtained when using $\left[\mathrm{C}_{2} \mathrm{mim}\right] \mathrm{Br}$ (NP1, NP2 and NP3 of Table 1$)$. The crystallinity is enhanced when the concentration of $\left[\mathrm{C}_{2} \mathrm{mim}\right] \mathrm{Br}$ is increased from $0.1 \%$ to $1 \mathrm{~mol} \%$ (Fig. $1 \mathrm{~b}$ ). By maintaining the same reaction conditions, if no IL is used, cubic $\mathrm{NaGdF}_{4}$ of an extremely low degree of crystallinity is obtained instead of hexagonal (ESI, Fig. S1 $\dagger$ ), indicating the significant role played by the IL on phase evolution. The peak related to the (110) plane of the hexagonal phase is the most intense and is distinctly broader 

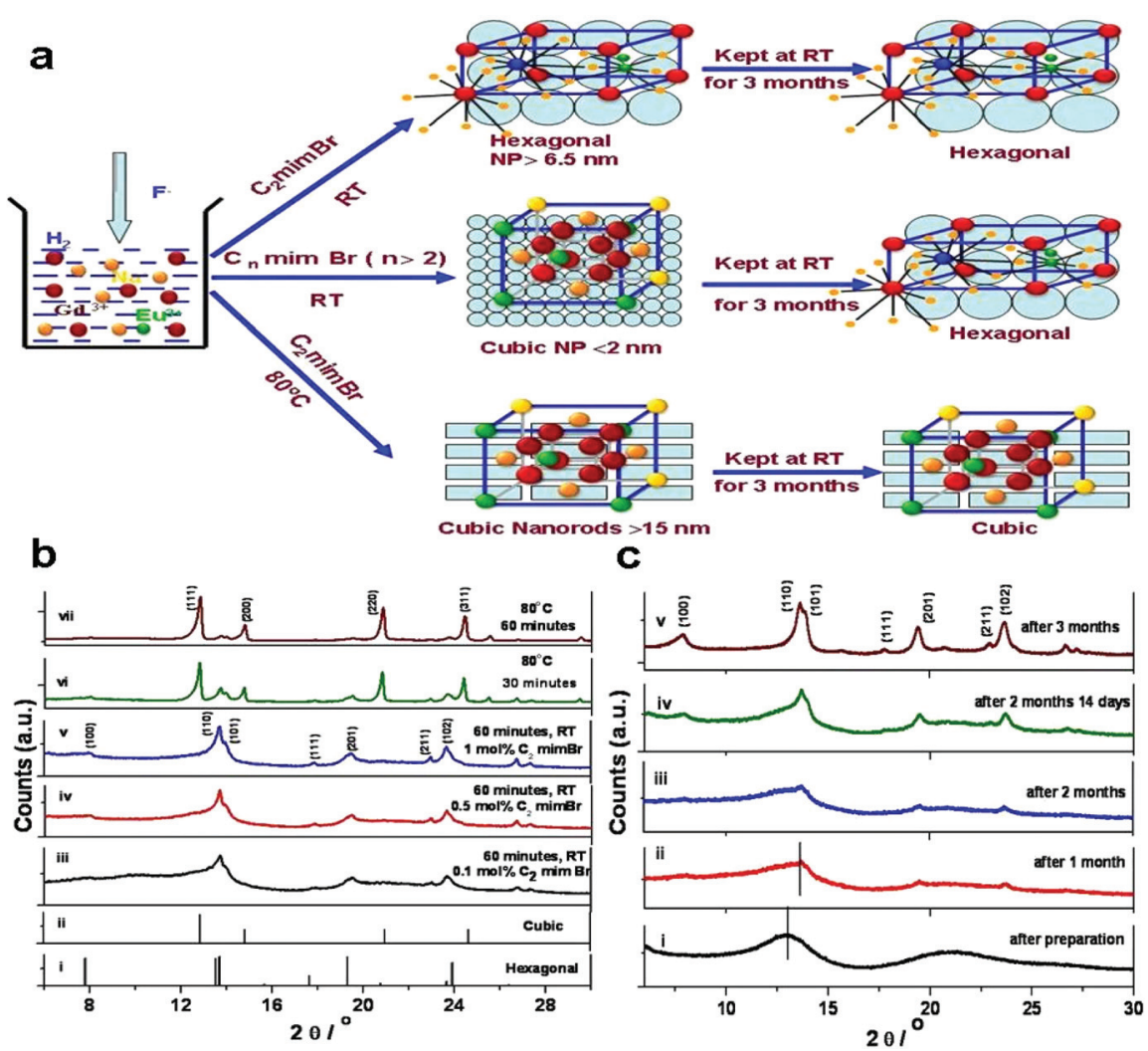

Fig. 1 (a) A general scheme illustrating the phase selective synthesis of Eu ${ }^{3+}$-doped $\mathrm{NaGdF}_{4}$ nanocrystals employing ILs and their subsequent crystal phase behaviour. (b) PXRD pattern of $\mathrm{NaGdF}_{4}: \mathrm{Eu}^{3+}$ nanocrystals prepared at different temperatures with different concentrations of IL; (i) hexagonal database pattern (JCPDS card no-27-699); (ii) cubic database pattern (JCPDS card no-27-697); (iii)-(v) doped $\mathrm{NaGdF}_{4}$ :Eu ${ }^{3+}$ prepared by $0.1,0.5$ and $1.0 \mathrm{~mol} \%\left[\mathrm{C}_{2} \mathrm{mim}\right] \mathrm{Br}$ respectively at $\mathrm{RT}$ and with 1 hour stirring; (vi) and (vii) $\mathrm{NaGdF}_{4}: \mathrm{Eu}^{3+}$ samples prepared at $80{ }^{\circ} \mathrm{C}$ and with $0.1 \mathrm{~mol} \%$ $\left[\mathrm{C}_{2}\right.$ mim] Br for 30 minutes and $\mathrm{NaGdF}_{4}: \mathrm{Eu}^{3+}$ samples prepared at a reaction time of 1 hour. (c) PXRD pattern of $\mathrm{NaGdF}_{4}: \mathrm{Eu}^{3+}$ nanocrystals prepared with $1 \mathrm{~mol} \%\left[\mathrm{C}_{4} \mathrm{mim}\right] \mathrm{Br}$ at $\mathrm{RT}$ and 1 hour stirring time. PXRD is taken after different time intervals of preparation.

than that of the (101) reflection, indicating an anisotropic, oriented growth of the hexagonal structure. It may be concluded that $\left[\mathrm{C}_{2} \mathrm{mim}\right] \mathrm{Br}$ acts as a capping agent and interacts strongly with the (110) plane inhibiting its growth. Potential interactions could originate from $\pi$-stacking between aromatic rings and hydrogen bonding between the initial nuclei facets and the $\mathrm{H}$ atom in the $\mathrm{C}(2)$ position of $\left[\mathrm{C}_{2} \mathrm{mim}\right]^{+}$. To understand the effect of hydrogen bonding, 1-ethyl-dimethylimidazolium bromide $\left[\mathrm{C}_{2} \mathrm{dmim}\right] \mathrm{Br}$, in which $\mathrm{C}(2)-\mathrm{H}$ is replaced by methyl, is used in a similar synthesis. Here also pure hexagonal material is obtained (Fig. S2a $\uparrow$ and NP21 of Table 1) suggesting that the evolution of the hexagonal phase is not affected by $\mathrm{H}$-bonding, but rather $\left[\mathrm{C}_{2} \mathrm{mim}\right]^{+}$ions are anchored on to the (110) plane via the $\pi$-system. To prove this, a quaternary ammonium IL, tetramethylammonium bromide $\left(\left[\mathrm{Me}_{4} \mathrm{~N}\right] \mathrm{Br}\right.$ ) is used which leads to cubic $\mathrm{NaGdF}_{4}$ (NP19 of Table 1). If $\left[\mathrm{C}_{2} \mathrm{mim}\right] \mathrm{Cl}$ is used instead of $\left[\mathrm{C}_{2} \mathrm{mim}\right] \mathrm{Br}$, again the hexagonal phase (NP20 of Table 1) appears (Fig. S2b $\dagger$ ) suggesting that indeed the $\pi$-system of the $\left[\mathrm{C}_{2} \mathrm{mim}\right]^{+}$cation is the key factor.

3.1.2 Effect of reaction temperature on phase evolution. A drastic change in phase evolution appears when the reaction temperature is changed from RT to $80^{\circ} \mathrm{C}$, with otherwise iden- tical parameters. Here the formation of quite well crystallized particles of the cubic phase with only small impurities of the hexagonal phase already appears after 30 minutes. When the reaction time is prolonged, the cubic phase becomes even more dominant (Fig. 1b and $\mathrm{S} 3 \dagger$ ). If the reaction is conducted at $80{ }^{\circ} \mathrm{C}$ without the presence of a $\left[\mathrm{C}_{2} \mathrm{mim}\right] \mathrm{IL}$, the cubic phase is also formed preferentially (Fig. S4†). This indicates that in the case of a fast reaction rate the less thermodynamically favoured $\mathrm{NaGdF}_{4}$ polymorph is formed, which is in agreement with Ostwald's step rule. At room temperature the $\left[\mathrm{C}_{2} \mathrm{mim}\right]^{+}$ cation apparently is able to interact with the $\mathrm{NaGdF}_{4}$ nuclei, slowing down the reaction rate and favouring the formation of the thermodynamically stable hexagonal modification. At higher reaction temperatures the $\left[\mathrm{C}_{2} \mathrm{mim}\right]^{+}$cation can bind less efficiently to the $\mathrm{NaGdF}_{4}$ surfaces and thus a mix of the two phases (cubic as the major one) appears. If the as-prepared hexagonal and cubic materials (NP1 and NP15 of Table 1) are heated to a higher temperature $\left(400{ }^{\circ} \mathrm{C}\right.$, for 5 hours), the hexagonal material retains its phase, but the cubic converts to hexagonal. No phase transitions are observed on cooling. This undoubtedly proves the thermodynamic stability of the hexagonal over the cubic phase (for details see the ESI, Fig. S5 and 6, and Scheme $\mathrm{S} 2 \dagger$ ). 
Table 1 Phase composition, crystallite size and reaction conditions to obtain nanocrystals using ILs. The crystallite size is estimated from the (110) diffraction peak of the hexagonal and (111) plane of the cubic material

\begin{tabular}{|c|c|c|c|c|c|}
\hline \multicolumn{2}{|c|}{ Name of the sample } & \multirow{2}{*}{$\begin{array}{l}\begin{array}{l}\text { IL concentration } \\
(\mathrm{mol} \%)\end{array} \\
0.1\left[\mathrm{C}_{2} \mathrm{mim}\right] \mathrm{Br}\end{array}$} & \multirow{2}{*}{$\begin{array}{l}\text { Reaction temperature } \\
\text { and time }\end{array}$} & \multirow{2}{*}{$\begin{array}{l}\text { Crystal phase } \\
\text { Hexagonal }\end{array}$} & \multirow{2}{*}{$\frac{\begin{array}{l}\text { Crystallite size } \\
(\mathrm{nm})\end{array}}{6.6( \pm 0.2)^{a}}$} \\
\hline NP1 & $\mathrm{NaGdF}_{4}: \mathrm{Eu}(2)$ & & & & \\
\hline NP3 & $\mathrm{NaGdF}_{4}: \mathrm{Eu}(2)$ & $1.0\left[\mathrm{C}_{2} \mathrm{mim}\right] \mathrm{Br}$ & RT (1 hour) & Hexagonal & $11.1( \pm 0.3)$ \\
\hline NP4 & $\mathrm{NaGdF}_{4}: \mathrm{Eu}(2)$ (measured after 3 months) & $1.0\left[\mathrm{C}_{2} \mathrm{mim}\right] \mathrm{Br}$ & RT (1 hour) & Hexagonal & $11.5( \pm 0.2)$ \\
\hline NP5 & $\mathrm{NaGdF}_{4}: \mathrm{Eu}(2)$ (measured after preparation) & $1.0\left[\mathrm{C}_{4} \mathrm{mim}\right] \mathrm{Br}$ & RT (1 hour) & Cubic & $\sim 1.5( \pm 0.2)$ \\
\hline NP6 & $\mathrm{NaGdF}_{4}: \mathrm{Eu}(2)$ (measured after 1 month) & $1.0\left[\mathrm{C}_{4} \mathrm{mim}\right] \mathrm{Br}$ & RT (1 hour) & Hexagonal & $4.8( \pm 0.2)$ \\
\hline NP9 & $\mathrm{NaGdF}_{4}: \mathrm{Eu}(2)$ (measured after 3 months) & $1.0\left[\mathrm{C}_{4} \mathrm{mim}\right] \mathrm{Br}$ & RT (1 hour) & Hexagonal & $8.2( \pm 0.2)$ \\
\hline NP10 & $\mathrm{NaGdF}_{4}: \mathrm{Eu}(2)$ (measured after preparation) & $1.0\left[\mathrm{C}_{8} \mathrm{mim}\right] \mathrm{Br}$ & RT (1 hour) & Cubic & $\sim 1.5( \pm 0.2)$ \\
\hline NP11 & $\mathrm{NaGdF}_{4}: \mathrm{Eu}(2)$ (measured after 3 months) & $1.0\left[\mathrm{C}_{8} \mathrm{mim}\right] \mathrm{Br}$ & RT (1 hour) & Hexagonal & $12.6( \pm 0.2)$ \\
\hline NP12 & $\mathrm{NaGdF}_{4}: \mathrm{Eu}(2)$ (measured after preparation) & $1.0\left[\mathrm{C}_{10} \mathrm{mim}\right] \mathrm{Br}$ & RT (1 hour) & Cubic & $\sim 1.5( \pm 0.2)$ \\
\hline NP13 & $\mathrm{NaGdF}_{4}: \mathrm{Eu}(2)$ (measured after 3 months) & $1.0\left[\mathrm{C}_{10} \mathrm{mim}\right] \mathrm{Br}$ & RT ( 1 hour) & Hexagonal & $7.1( \pm 0.2)$ \\
\hline NP14 & $\mathrm{NaGdF}_{4}: \mathrm{Eu}(2)$ & $0.1\left[\mathrm{C}_{2} \mathrm{mim}\right] \mathrm{Br}$ & $80^{\circ} \mathrm{C}$ (30 minutes) & Cubic & $14.0( \pm 0.2)$ \\
\hline NP15 & $\mathrm{NaGdF}_{4}: \mathrm{Eu}(2)$ & $0.1\left[\mathrm{C}_{2} \mathrm{mim}\right] \mathrm{Br}$ & $80^{\circ} \mathrm{C}(1$ hour $)$ & Cubic & $18.1( \pm 0.2)$ \\
\hline NP20 & $\mathrm{NaGdF}_{4}: \mathrm{Eu}(2)$ & $1.0\left\lceil\mathrm{C}_{2} \mathrm{mim}\right\rceil \mathrm{Cl}$ & RT ( 1 hour) & Hexagonal & $12.0( \pm 0.3)$ \\
\hline NP21 & $\mathrm{NaGdF}_{4}: \mathrm{Eu}(2)$ & $1.0\left[\mathrm{C}_{2} \mathrm{dmim}\right] \mathrm{Br}$ & RT (1 hour) & Hexagonal & $10.0( \pm 0.3)$ \\
\hline
\end{tabular}

${ }^{a}$ Estimated deviation, $\mathrm{RT}=$ room temperature, $\mathrm{NaGdF}_{4}: \mathrm{Eu}(2)=\mathrm{NaGdF}_{4}$ doped with $2 \mathrm{~mol} \% \mathrm{Eu}^{3+}$.

3.1.3 Effect of alkyl chain length of IL and spontaneous phase transition. When the alkyl chain length at the $\mathrm{C}(1)$ position of the imidazolium ring is extended to four or more carbon atoms as in $\left[\mathrm{C}_{4} \mathrm{mim}\right] \mathrm{Br},\left[\mathrm{C}_{8} \mathrm{mim}\right] \mathrm{Br}$ or $\left[\mathrm{C}_{10} \mathrm{mim}\right] \mathrm{Br}$, instead of getting hexagonal $\mathrm{NaGdF}_{4}$ (as for $\left[\mathrm{C}_{2} \mathrm{mim}\right] \mathrm{Br}$ ), cubic phased material of a comparatively low degree of crystallinity is obtained (Fig. 1c and $\mathrm{S} 7 \dagger$ ). The PXRD patterns are quite similar to those where no IL was used (Fig. S1 $\dagger$ ). This result clearly indicates that unlike $\left[\mathrm{C}_{2} \mathrm{mim}\right] \mathrm{Br}$, imidazolium cations bearing longer alkyl chains have difficulty in interacting with the primary nuclei facets due to steric hindrance. Interestingly, the as-prepared samples (NP5) of the cubic phase convert completely to the hexagonal phase if kept at room temperature. Only one month after its preparation, reflections of the hexagonal phase start to appear (NP6), becoming more prominent after 2 months and 14 days (NP8) and completely crystalline hexagonal phase material is present after 3 months (Fig. 1c and NP9). Here the PXRD patterns are checked in regular intervals of 7 days.

Similar phenomena are observed for $\left[\mathrm{C}_{n} \mathrm{mim}\right] \mathrm{Br},(n=4,8$, 10) (Fig. S7†). This kind of spontaneous conversion from the cubic to pure hexagonal phase with time is new and previously undocumented to the best of our knowledge. However, the $\left[\mathrm{C}_{2} \mathrm{mim}\right] \mathrm{Br}$ mediated hexagonal (NP1-3 of Table 1 ) and the cubic phase material obtained from the reaction at elevated temperature $\left(80{ }^{\circ} \mathrm{C}\right.$, NP15 of Table 1$)$ did not undergo this phase change (Fig. S8 $\dagger$ ). When analyzing the crystallite size (Table 1), it is seen that there exists a critical size for the cubic to hexagonal phase transition at room temperature: prepared under similar conditions but with $\left[\mathrm{C}_{4} \mathrm{mim}\right] \mathrm{Br}$, sample NP5 has an average crystallite size of $\sim 1.5 \mathrm{~nm}$. After 3 months, when conversion to the hexagonal phase has occurred, the crystal size becomes $8.2 \mathrm{~nm}$. However, the cubic material obtained
(NP15) at a higher reaction temperature $\left(80^{\circ} \mathrm{C}\right)$ is much larger (18.1 nm) and does not change its phase with time. It is known that phase transformation in nanoparticles is governed by interface nucleation and surface energies. ${ }^{59-62}$ When the particle size is small, the surface energy is high which facilitates the transformation to the thermodynamically more stable phase. When the particles are larger the surface energy is less and additional activation energy is required for the phase transition. In summary, we observe that whenever the IL cation is able to attach to the surface, the reaction is slowed down to such an extent that the thermodynamically stable (hexagonal) polymorph forms, as seen for $\left[\mathrm{C}_{2} \mathrm{mim}\right] \mathrm{Br}$.

In the case of high reaction rates, when the IL cannot interact via the $\pi$-system with the $\mathrm{NaGdF}_{4}$ nuclei due to steric hindrance or elevated reaction temperatures, the thermodynamically less stable cubic polymorph forms, in accordance with Ostwald's step rule. When the particles are small, the surface energy is high and the particles easily undergo a phase transition from the less thermodynamically stable to the more stable form (see the scheme in Fig. 1a and 1c). However, when the particles are larger, activation energy must be provided to provoke the phase transition.

\subsection{Lattice strain and phase evolution}

Generally, the broadening of the diffraction peaks depends upon strain and crystallite size. It is possible to calculate the lattice strain according to the function derived by Williamson and Hall: ${ }^{64}$

$$
\beta \cos \theta / \lambda=1 / D+\eta \sin \theta / \lambda
$$

where $\beta$ is the full width at half maximum (fwhm), $\theta$ is the diffraction angle, $\lambda$ is the X-ray wavelength, $D$ is the effective 
crystallite size, and $\eta$ is the effective strain. When plotting $\beta \cos \theta / \lambda$ against $\sin \theta / \lambda$ the strain can be derived from the slope and the crystallite size $(D)$ is given by the intercept of the plot (Fig. 2). ${ }^{60}$ An extremely high compressive strain of $-14.3 \%$ is observed for cubic $\mathrm{NaGdF}_{4}: \mathrm{Eu}(2)$ obtained from $1.0 \mathrm{~mol} \%$ $\left[\mathrm{C}_{4} \mathrm{mim}\right] \mathrm{Br}$ at room temperature (sample NP5, Tables 1 and 2). According to both the Williamson-Hall and the Scherrer equation a crystallite size of $1-1.5 \mathrm{~nm}$ is derived (Tables 1 and 2). When the sample is kept for 1 and 2 months at room temperature after its preparation (NP6 and NP7), the lattice strain decreases significantly to $-5.42 \%$ and finally to $-0.796 \%$ (Table 2) and a phase transition from cubic to hexagonal is observed. At the same time the crystallite size grows from $1.1 \mathrm{~nm}$ (for the sample measured after preparation) to 4.69 and $8.2 \mathrm{~nm}$ respectively (for the sample measured after one and two months respectively). After 2.5 months from the preparation, the lattice strain and crystallite size stops changing significantly (Table 2). A reversed lattice strain i.e. tensile strain $(+0.21 \%)$ is observed for the cubic material (NP15) obtained from $0.1 \mathrm{~mol} \%\left[\mathrm{C}_{2} \mathrm{mim}\right] \mathrm{Br}$ at $80{ }^{\circ} \mathrm{C}$ (Fig. 2a and b). For $2 \mathrm{~mol} \% \mathrm{Eu}^{3+}$-doped hexagonal $\mathrm{NaGdF}_{4}$ (NP1) prepared by $0.1 \mathrm{~mol} \%\left[\mathrm{C}_{2} \mathrm{mim}\right] \mathrm{Br}$ at room temperature, a small compressive strain of $-1.26 \%$ is observed and the crystallite size is calculated as $8.44 \mathrm{~nm}$, which is in good agreement with the value obtained from the Scherrer equation (Table 1).

\subsection{Structural characterization by transmission electron microscopy}

To understand the phase evolution from its atomistic origin, TEM images are analyzed in detail. Fig. 3a, b and S10† show

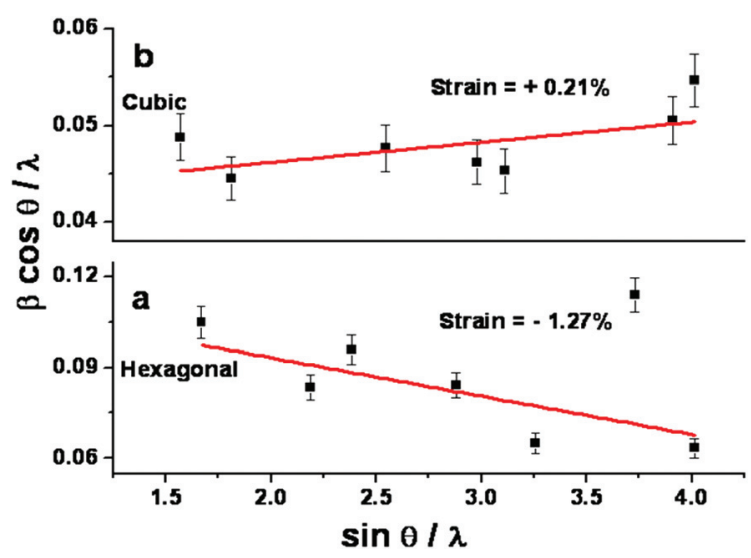

Fig. 2 Plot of $\beta \cos \theta / \lambda$ against $\sin \theta / \lambda$ for $\mathrm{NaGdF}_{4}$ : $\mathrm{Eu}(2)$ prepared by $0.1 \mathrm{~mol} \%\left[\mathrm{C}_{2} \mathrm{mim}\right] \mathrm{Br}$ at room temperature (a) and at $80^{\circ} \mathrm{C}(\mathrm{b})$. the low magnification images of $\mathrm{NaGdF}_{4}$ nanocrystals prepared using various concentrations of $\left[\mathrm{C}_{2} \mathrm{mim}\right] \mathrm{Br}$ (NP1-NP3 of Table 1). The nanostructures obtained appear to be built up by intergrown nanocrystals of slightly elongated shape. The average aspect ratio (particle length/particle diameter) increases slightly with increasing IL concentration. It appears that the IL evokes a preferential growth of $\mathrm{NaGdF}_{4}$ crystal nuclei in certain directions by selectively attaching to growth facets, thus allowing the nanocrystals to undergo selforganization into the desired nanostructure, just as a soft template. $^{45}$

HRTEM images have shown that for rod-shaped $\mathrm{NaGdF}_{4}$ nanocrystals, an imperfect oriented attachment via the low energy plane (110) among the multiple nanorods separated by a twin boundary occurs (Fig. 3d). ${ }^{65}$ Normally twins are formed when coherence is achieved in the interfacial plane. A series of dislocations is observed due to small misorientation in the interface as indicated by arrow heads (Fig. 3d). This lattice mismatch arises when the surfaces of adjacent oriented particles are not atomically flat.

Importantly, the dominant exposed plane of hexagonal $\mathrm{NaGdF}_{4}$ is consistently (110) (Fig. $3 \mathrm{~d}$ and $\mathrm{S} 11 \dagger$ ). So it can be inferred that the $\left[\mathrm{C}_{2} \mathrm{mim}\right]^{+}$ion serves as a capping agent based on the strong interaction with the (110) facets which favour the directional growth of the hexagonal phase. As the most exposed facets of the $\mathrm{NaGdF}_{4}$ nanorods are the (110) planes or symmetrical equivalents, the energy difference between them is minimal, facilitating the oriented attachment. Though the crystal phase remains constant, the morphology changes if 1-ethyl-2,3-dimethylimidazolium bromide $\left(\left[\mathrm{C}_{2} \mathrm{dmim}\right] \mathrm{Br}\right)$ is used instead of $\left[\mathrm{C}_{2} \mathrm{mim}\right] \mathrm{Br}$ (Fig. 3c). Instead of nanorods, spherical particles with an average diameter of $10 \mathrm{~nm}$ are obtained. It is assumed that in the case of $\left[\mathrm{C}_{2} \mathrm{mim}\right] \mathrm{Br}$, a stronger directional interaction of the imidazole ring with the growth facets of hexagonal $\mathrm{NaGdF}_{4}$ occurs, promoted through the acidic hydrogen atom in the 2-position of the imidazolium ring. When the latter is replaced by a methyl group, hydrogen bonding becomes weaker, the interaction between $\left[\mathrm{C}_{2} \mathrm{dmim}\right]$ cations and $\mathrm{NaGdF}_{4}$ nuclei facets is less and $\mathrm{NaGdF}_{4}$ can grow more isotropic, thus producing nanoparticles. The measured lattice spacings (Fig. $3 \mathrm{e}$ ) of the $\left[\mathrm{C}_{2} \mathrm{dmim}\right] \mathrm{Br}$ mediated sample belong to the (110) plane of the hexagonal phase, as further confirmed by the FFT (fast Fourier transform) pattern (Fig. 3f). However, a significant change in morphology along with the crystal phase is observed if the reaction temperature is raised from RT to $80^{\circ} \mathrm{C}$, keeping the concentration of $\left[\mathrm{C}_{2} \mathrm{mim}\right] \mathrm{Br}$ the same (Fig. S12e and $f \dagger$ ). Flower-like nanoaggregates with nano-

Table 2 Lattice strain of $\mathrm{NaGdF}_{4}: \mathrm{Eu}(2)$ prepared from $1.0 \mathrm{~mol} \%\left[\mathrm{C}_{4} \mathrm{mim}\right] \mathrm{Br}$ at room temperature

\begin{tabular}{|c|c|c|c|c|c|}
\hline $\begin{array}{l}\mathrm{NaGdF}_{4}: \mathrm{Eu}(2) \\
\left(0.1\left[\mathrm{C}_{4} \mathrm{mim}\right] \mathrm{Br}, \mathrm{RT}\right)\end{array}$ & $\begin{array}{l}\text { Freshly prepared } \\
\text { sample (NP5) }\end{array}$ & $\begin{array}{l}\text { After } 1 \text { month } \\
\text { (NP6) }\end{array}$ & $\begin{array}{l}\text { After } 2 \text { months } \\
\text { (NP7) }\end{array}$ & $\begin{array}{l}\text { After } 2.5 \text { months } \\
\text { (NP8) }\end{array}$ & $\begin{array}{l}\text { After } 3 \text { months } \\
\text { (NP9) }\end{array}$ \\
\hline Crystal phase & Cubic & Hexagonal & Hexagonal & Hexagonal & Hexagonal \\
\hline Crystallite size & $1.09 \mathrm{~nm}$ & $4.69 \mathrm{~nm}$ & $8.24 \mathrm{~nm}$ & $8.60 \mathrm{~nm}$ & $8.62 \mathrm{~nm}$ \\
\hline
\end{tabular}




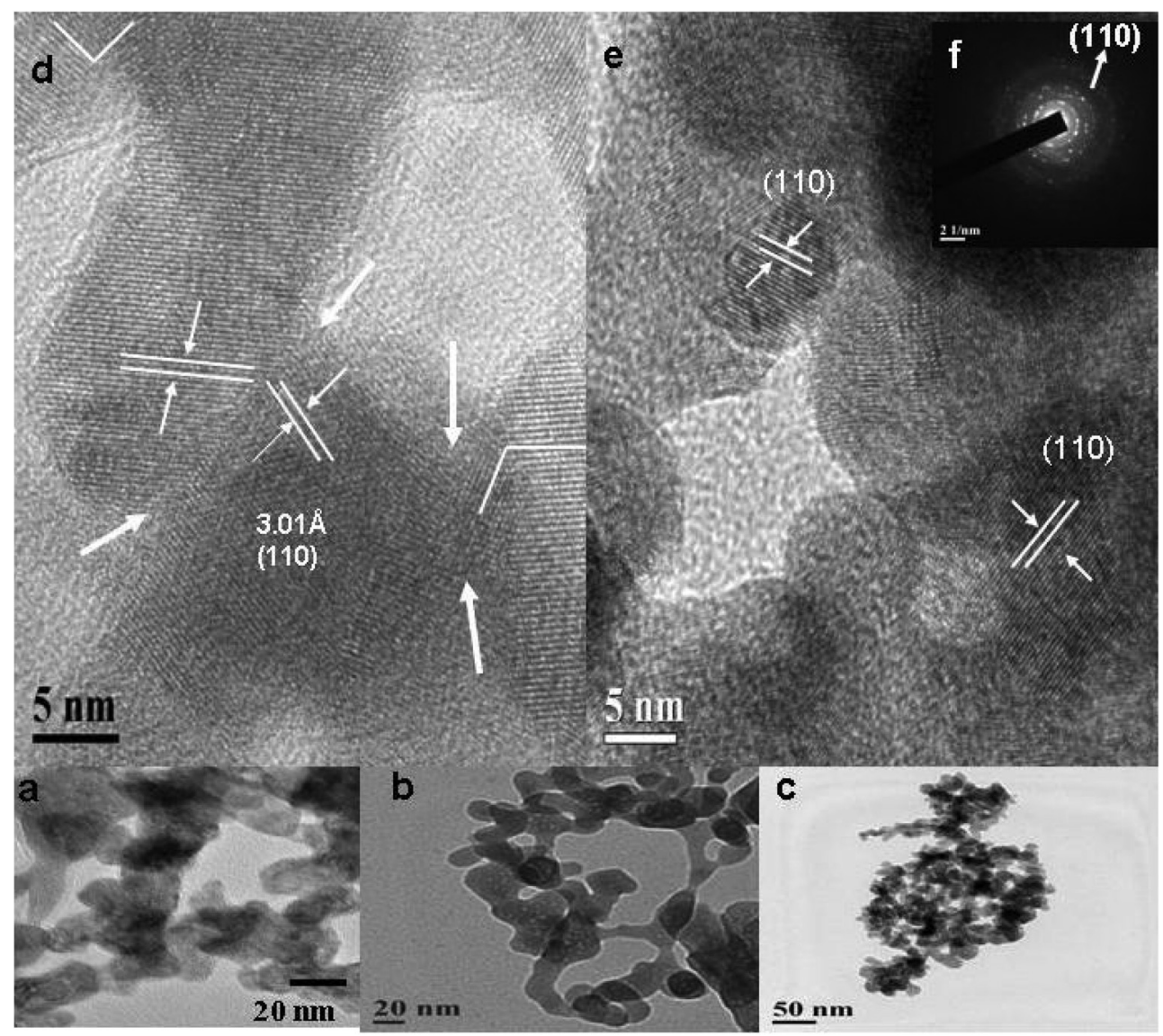

Fig. 3 (a) and (b) Low magnification TEM images of $\mathrm{NaGdF}_{4}$ : $\mathrm{Eu}^{3+}$ nanocrystals of the hexagonal phase prepared at room temperature (RT), in the presence of 0.1 and 1.0 mol\% $\left[\mathrm{C}_{2} \mathrm{mim}\right] \mathrm{Br}$, respectively; (d) HRTEM image of $\mathrm{NaGdF}_{4}: \mathrm{Eu}^{3+}$ nanocrystals prepared at RT and in the presence of $1.0 \mathrm{~mol} \%\left[\mathrm{C}_{2} \mathrm{mim}\right] \mathrm{Br}$; (c), (e) and (f) TEM, HRTEM and FFT pattern of hexagonal phase nanocrystals prepared at RT with $1 \mathrm{~mol} \%$ [C $\left.2 \mathrm{dmim}\right] \mathrm{Br}$.

discs and nanorods are observed, which on further heating agglomerate to sphere-like aggregates and complete spheres (Fig. S12g and $\mathrm{h} \dagger$ ) indicating that the IL no longer efficiently can shield against particle agglomeration.

Fig. 4a and b depict the low magnification images of the $\mathrm{NaGdF}_{4}$ samples using $\left[\mathrm{C}_{4} \mathrm{mim}\right] \mathrm{Br}$ at room temperature (NP5 and NP9 of Table 1). Fig. 4a is measured immediately after preparation, whereas Fig. $4 \mathrm{~b}$ is after 3 months. Here also spherical particles are obtained, despite the acidic 2-H proton of the imidazolium ring. It seems that the steric requirements of the butyl side chain lead to a reduced interaction of the imidazolium cation with the primary nuclei. When ILs with even longer alkyl chains such as $\left[\mathrm{C}_{10} \mathrm{mim}\right] \mathrm{Br}$ are used, the cation is no longer able to interact with the primary nuclei and the same results are obtained (Fig. S13†).

To understand the phase conversion over time from its atomistic origin, HRTEM images were analyzed carefully (Fig. 4c and d). The measured lattice spacing in Fig. $4 \mathrm{c}$ for the as-prepared samples (NP5) clearly belongs to the (200) plane of cubic $\mathrm{NaGdF}_{4}$. The smallest particle size also is below $5 \mathrm{~nm}$ (considering the lattice fringes in the circled area of Fig. 4c). Interestingly, lattice planes in one region are not connected to others (e.g. area $\mathrm{A}$ and $\mathrm{B}$ or $\mathrm{C}$ and $\mathrm{D}$ in Fig. 4c).
However, HRTEM images measured after three months of the sample preparation (NP9) are entirely different (Fig. 4d). The average diameter of the nanocrystals has grown to $\sim 15 \mathrm{~nm}$ and the measured lattice spacing belongs to the (110) plane of hexagonal $\mathrm{NaGdF}_{4}$. Now the lattice planes are connected and defect structures can also be observed in some areas, as circled (Fig. 4d). The analysis clearly demonstrates that the particle undergoes Ostwald ripening with time, growing and transforming to the more thermodynamically stable form. The presence of proper elemental compositions was confirmed by energy dispersive X-ray analysis (EDXA) (Fig. S14†).

\subsection{Optical characterizations}

Fig. 5A, $\mathrm{C}$ and $\mathrm{E}$ show the room temperature photoluminescence (PL) spectra of $\mathrm{NaGdF}_{4}: \mathrm{Eu}^{3+}$ nanocrystals in the hexagonal modification (NP1, NP2 and NP3 of Table 1) obtained with different concentrations of $\left[\mathrm{C}_{2} \mathrm{mim}\right] \mathrm{Br}$ under direct excitation of the ${ }^{7} \mathrm{~F}_{0}{ }^{-5} \mathrm{~L}_{6}$ transition of the $\mathrm{Eu}^{3+}$ ion $\left(\lambda_{\mathrm{ex}}=\right.$ $393 \mathrm{~nm}$ ). (The details of the excitation spectra measured at room and liquid nitrogen temperature $(77 \mathrm{~K})$ are given in the ESI (Fig. S15 and 16)†). The most prominent emission bands appear at 615 and $592 \mathrm{~nm}$ which originate from the ${ }^{5} \mathrm{D}_{0}-{ }^{7} \mathrm{~F}_{2}$ (electric dipole, $e$ ) and ${ }^{5} \mathrm{D}_{0}{ }^{-7} \mathrm{~F}_{1}$ (magnetic dipole, $m$ ) transitions 


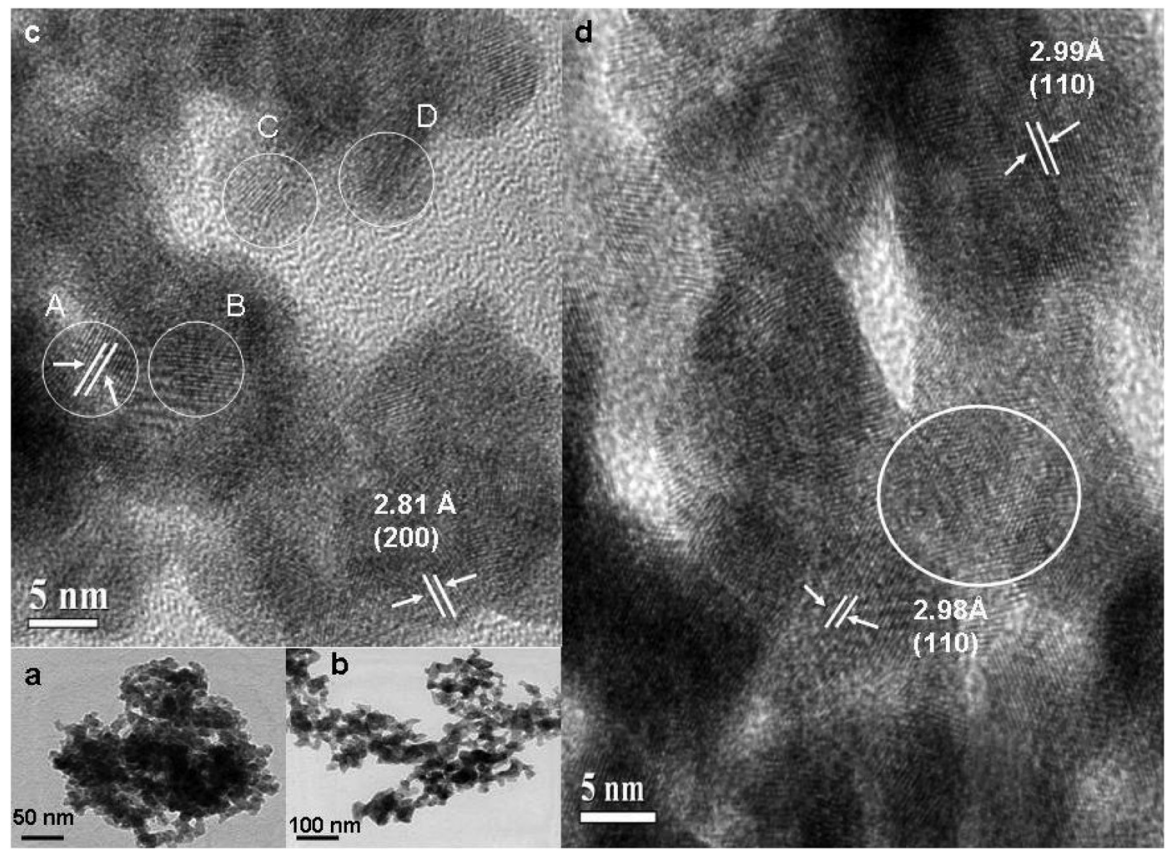

Fig. 4 (a) and (b) Low magnification TEM images of $\mathrm{NaGdF}_{4}: \mathrm{Eu}^{3+}$ nanocrystals prepared at $\mathrm{RT}$ and in the presence of $1.0 \mathrm{~mol} \%\left[\mathrm{C}_{4}\right.$ mim] $\mathrm{Br}$ (measured just after preparation and after 3 months); (c) and (d) HRTEM images of $\mathrm{NaGdF}_{4}: \mathrm{Eu}^{3+}$ nanocrystals prepared at RT and in the presence of $1.0 \mathrm{~mol} \%\left[\mathrm{C}_{4} \mathrm{mim}\right] \mathrm{Br}$ (measured just after preparation and after 3 months).

respectively, in addition to transitions from higher ${ }^{5} \mathrm{D}_{J}(J=$ 1-3) levels to the ${ }^{7} \mathrm{~F}$ manifold. The hypersensitive forced electric dipole transition is more intense than the magnetic dipole and increases relative to the magnetic dipole with increasing IL concentration. For better understanding and quantification, the respective asymmetry parameter $\left(\Omega_{2}\right)$ using Judd-Ofelt theory was calculated. ${ }^{66,67}$ It is seen that the $\mathrm{J}-\mathrm{O}$ parameter $\left(\Omega_{2}\right)$ steadily increases with increasing IL concentration and points to attainment of an increasingly less symmetric environment for the $\mathrm{Eu}^{3+}$ ion (the J-O parameter $\left(\Omega_{2}\right)$ is $6.69 \times 10^{-20}$ $\mathrm{cm}^{2}, 9.88 \times 10^{-20} \mathrm{~cm}^{2}$, and $12.29 \times 10^{-20} \mathrm{~cm}^{2}$ for $0.1,0.5$ and $1.0 \mathrm{~mol} \%\left[\mathrm{C}_{2} \mathrm{mim}\right] \mathrm{Br}$ IL respectively) as expected for an increasingly crystalline hexagonal material (for details see the ESI $\dagger$ ). When the reaction temperature is raised from RT to $80^{\circ} \mathrm{C}$, cubic nanocrystals (NP15) form (Fig. 1b) and the nature of the spectrum also changes (Fig. 5B). Here the magnetic dipole becomes more prominent than the electric dipole transition. The lower $\Omega_{2}$ value $\left(4.29 \times 10^{-20} \mathrm{~cm}^{2}\right)$ of the cubic material compared to that of the hexagonal $\left(6.69 \times 10^{-20} \mathrm{~cm}^{2}\right)$ indicates a higher site symmetry of the $\mathrm{Eu}^{3+}$ ion in the cubic phase which is expected from the crystal structure.

Fig. 5D and F represent the PL spectra recorded at $-196{ }^{\circ} \mathrm{C}$ for the sample obtained with 0.5 and $1.0 \mathrm{~mol} \%\left[\mathrm{C}_{2} \mathrm{mim}\right] \mathrm{Br}$ at $\mathrm{RT}$ under direct excitation. Interestingly, the transitions from higher levels such as ${ }^{5} \mathrm{D}_{1}$ increase significantly compared to RT measurements, due to a decreased multiphonon relaxation between the higher ${ }^{5} \mathrm{D}$ levels at lower temperatures. Luminescence lifetime measurements show that the ${ }^{5} \mathrm{D}_{1}$ lifetime increases by a factor of $\sim 2$ (from 1.77 to $3.82 \mathrm{~ms}$ ) upon lower-

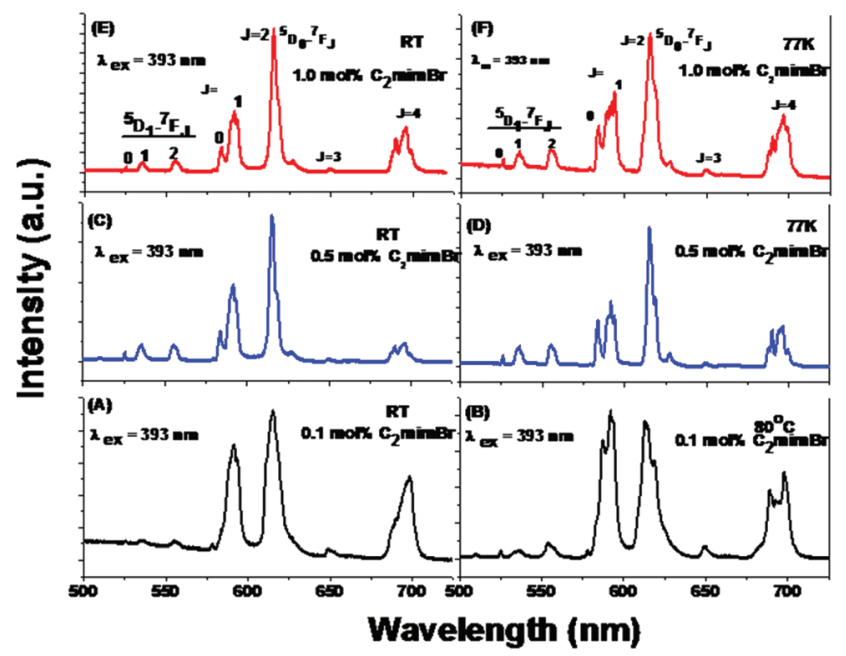

Fig. 5 (A) and (B) Emission spectra of $\mathrm{NaGdF}_{4}: \mathrm{Eu}^{3+}$ nanocrystals measured at RT and prepared in the presence of $0.1 \mathrm{~mol} \%\left[\mathrm{C}_{2} \mathrm{mim}\right] \mathrm{Br}$ at $\mathrm{RT}$ and $80^{\circ} \mathrm{C}$. (C) and (E) Emission spectra for the $0.5 \mathrm{~mol} \%$ and $1.0 \mathrm{~mol} \%$ $\left[\mathrm{C}_{2}\right.$ mim] Br mediated sample measured at RT. (D) and (F) Emission spectra of nanocrystals prepared in the presence of $0.5 \mathrm{~mol} \%\left[\mathrm{C}_{2} \mathrm{mim}\right] \mathrm{Br}$ at RT and $1.0 \mathrm{~mol} \%\left[\mathrm{C}_{2} \mathrm{mim}\right] \mathrm{Br}$ at RT $(\mathrm{F})$, measured at $-196{ }^{\circ} \mathrm{C}$. (Excitation wavelength $\lambda_{\text {exc }}=393 \mathrm{~nm}$ ).

ing the temperature from RT to $-196{ }^{\circ} \mathrm{C}$ whereas the ${ }^{5} \mathrm{D}_{0}$ lifetime increases only by $3 \%$ (from 11.29 to $11.64 \mathrm{~ms}$ ) under the same conditions (Fig. S17-S19†). The transitions from higher levels such as ${ }^{5} \mathrm{D}_{1}$ also decrease drastically when the 
$\mathrm{Eu}^{3+}$ concentration is increased from 0.5 to $10 \mathrm{~mol} \%$, due to concentration quenching (Fig. S20†).

\subsection{Understanding the spontaneous phase transition using $\mathrm{Eu}^{3+}$ ions as a spectroscopic probe}

The photoluminescence properties of $\mathrm{NaGdF}_{4}: \mathrm{Eu}^{3+}$ synthesized in the presence of $1 \mathrm{~mol} \%\left[\mathrm{C}_{4} \mathrm{mim}\right] \mathrm{Br}$ change as expected with time (Fig. 6). PL measurements immediately after sample preparation (NP5) show a slightly stronger magnetic dipole transition compared to the electric dipole suggesting high site symmetry of the $\mathrm{Eu}^{3+}$ dopant ion. When samples are measured one, two and three months after preparation, the electric dipole transition increases gradually (see the $e / m$ ratio in Fig. 6), indicating the cubic to hexagonal phase transformation. Likewise, the calculated Judd-Ofelt $\left(\Omega_{2}\right)$ parameters gradually increase with time, reaching a maximum for samples measured 3 months after preparation. The $\Omega_{2}$ values are $6.45 \times 10^{-20} \mathrm{~cm}^{2}, 6.97 \times 10^{-20} \mathrm{~cm}^{2}$, and $9.79 \times 10^{-20}$ $\mathrm{cm}^{2}$ for samples measured one, two and three months after preparation (ESI $\dagger$ ). This confirms the attainment of highly asymmetric site symmetry for $\mathrm{Eu}^{3+}$ as expected for a hexagonal material. Similar trends are observed for the samples prepared in the presence of $\left[\mathrm{C}_{8} \mathrm{mim}\right] \mathrm{Br}$ and $\left[\mathrm{C}_{10} \mathrm{mim}\right] \mathrm{Br}$ (Fig. S21 $\dagger$ ). As expected, no change in $\mathrm{PL}$ with time is noticed for the $\left[\mathrm{C}_{2} \mathrm{mim}\right] \mathrm{Br}$ mediated hexagonal samples as its phase remains unchanged over time (Fig. S22 $\dagger$ ). Thus, the $\mathrm{Eu}^{3+}$ ion has been successfully used as a spectroscopic probe to monitor the phase transformation.

\subsection{Vacuum-UV spectroscopy using synchrotron radiation}

In the vacuum-UV (VUV) excitation spectrum (Fig. S23†) the $\mathrm{Eu}^{3+}-\mathrm{F}^{-}$charge transfer (CT) band below $180 \mathrm{~nm}$ is apparent but, most importantly, no $\mathrm{Eu}^{3+}-\mathrm{O}^{2-} \mathrm{CT}$ band is observed. ${ }^{10}$

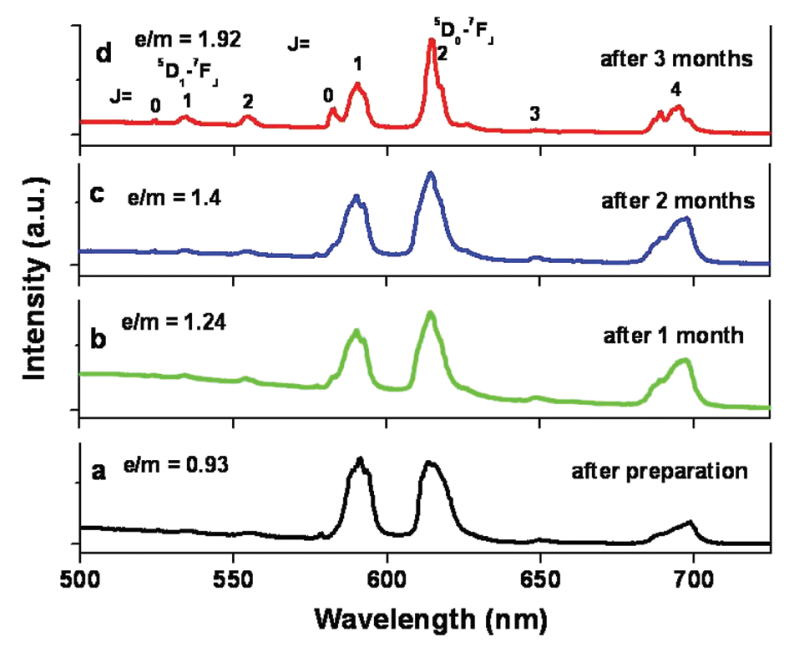

Fig. 6 Understanding of the spontaneous cubic-to-hexagonal phase transition using $\mathrm{Eu}^{3+}$ as a spectroscopic probe. (a)-(d) Emission spectra of $\mathrm{NaGdF}_{4}: \mathrm{Eu}^{3+}$ nanocrystals measured at RT and prepared with 1 mol\% $\left[\mathrm{C}_{4}\right.$ mim]Br upon excitation at $393 \mathrm{~nm}$ (right after preparation, after one month, after 2 months and after 3 months respectively).

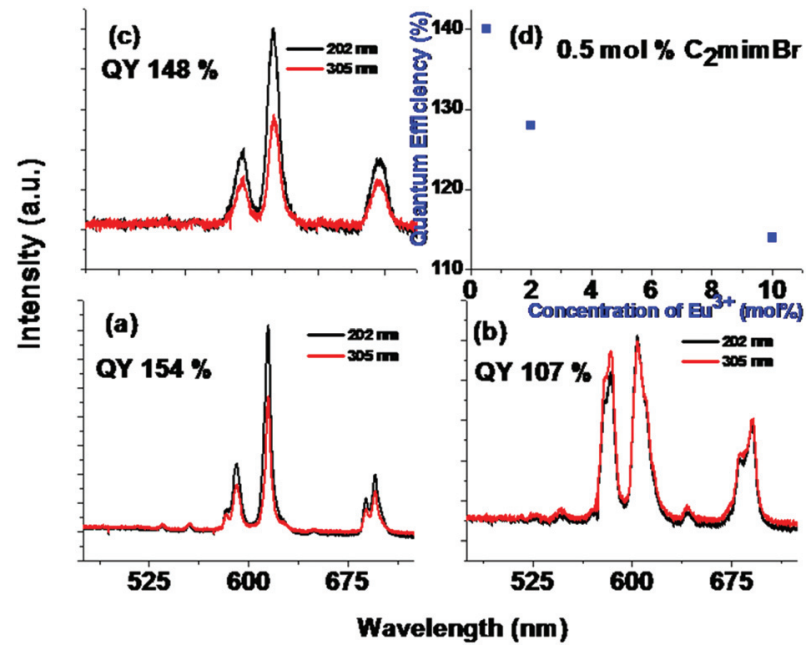

Fig. 7 Measurements of quantum cutting using synchrotron radiation. (a) and (b) Emission spectra of $\mathrm{NaGdF}_{4}: \mathrm{Eu}(2)$ nanocrystals prepared at RT in the presence of $1 \mathrm{~mol} \%\left[\mathrm{C}_{2} \mathrm{mim}\right] \mathrm{Br}$ and at $80^{\circ} \mathrm{C}$ in the presence of $0.1 \mathrm{~mol} \%\left[\mathrm{C}_{2} \mathrm{mim}\right] \mathrm{Br}$. (c) At RT in the presence of $1 \mathrm{~mol} \%\left[\mathrm{C}_{10} \mathrm{mim}\right] \mathrm{Br}$ (after 3 months of preparation). (d) The effects of the concentration of $\mathrm{Eu}^{3+}$ on the quantum efficiency for the hexagonal samples prepared in the presence of $0.5 \mathrm{~mol} \%\left[\mathrm{C}_{2} \mathrm{mim}\right] \mathrm{Br}$. The samples are excited in the ${ }^{6} \mathrm{G}_{\mathrm{J}}$ levels of $\mathrm{Gd}^{3+}$ at $202 \mathrm{~nm}$ (black) and in the ${ }^{6} \mathrm{P}_{\mathrm{J}}$ levels at $305 \mathrm{~nm}$ (red).

This confirms the absence of oxygen impurities in the sample. The emission spectra of pure hexagonal and cubic $\mathrm{NaGdF}_{4}$ : $\mathrm{Eu}^{3+}$ nanocrystals recorded with high intensity VUV synchrotron radiation are depicted in Fig. 7. Upon excitation into the ${ }^{6} \mathrm{G}_{J}$ level (202 nm), quantum cutting through a two-step energy transfer can occur. In the first step, cross relaxation $\mathrm{Gd}^{3+}\left({ }^{6} \mathrm{G}_{J}\right)$, $\mathrm{Eu}^{3+}\left({ }^{7} \mathrm{~F}_{0}\right) \rightarrow \mathrm{Gd}^{3+}\left({ }^{6} \mathrm{P}_{J}\right), \mathrm{Eu}^{3+}\left({ }^{5} \mathrm{D}_{0}\right)$ generates one photon and, in the second step, energy is transferred from the ${ }^{6} \mathrm{P}_{J}$ level of $\mathrm{Gd}^{3+}$ to a higher energy level of $\mathrm{Eu}^{3+}$, yielding an emission with a normal branching ratio for the different ${ }^{5} \mathrm{D}_{J}$ emission lines. ${ }^{1}$

As the first energy transfer step only gives emission from the ${ }^{5} \mathrm{D}_{0}$ level, a significant increase of its relative intensity upon excitation in the ${ }^{6} \mathrm{G}_{J}$ level is expected if quantum cutting happens. When excited by $305 \mathrm{~nm}\left({ }^{6} \mathrm{P}_{J}\right)$, a single energy transfer step to $\mathrm{Eu}^{3+}$ occurs with a normal branching ratio (Fig. S24 $\dagger$ ). Comparing the PL spectra of different incident wavelengths, it is seen that the intensity of the ${ }^{5} \mathrm{D}_{0}$ emission line is significantly higher for excitation in the ${ }^{6} \mathrm{G}_{J}$ levels than the ${ }^{6} \mathrm{P}_{J}$ levels, confirming the occurrence of quantum cutting for the hexagonal samples (Fig. 7 and Table S1 $\dagger$ ). The intensity ratios of ${ }^{5} \mathrm{D}_{0} /{ }^{5} \mathrm{D}_{1,2,3}$ were calculated both for the ${ }^{6} \mathrm{G}_{J}$ and ${ }^{6} \mathrm{P}_{J}$ level excitation for the hexagonal (Fig. 7a and c and NP3 and NP13 of Table 1) and the efficiencies of the cross relaxation step are determined to be $54 \%$ and $48 \%$, respectively. ${ }^{1}$ Consequently, high visible quantum efficiencies of $154 \%$ and $148 \%$ are achieved. However, for the cubic sample (Fig. 7b, NP15 of Table 1), the ${ }^{5} \mathrm{D}_{0}$ emission line for both the ${ }^{6} \mathrm{G}_{J}$ and ${ }^{6} \mathrm{P}_{J}$ excitations is almost similar indicating little to no quantum cutting (107\%). Detrimental effects of a high dopant concentration on quantum cutting are also witnessed although the crystal phase is the same (Fig. 7d). Such as for $\mathrm{NaGdF}_{4}: \mathrm{Eu}(10)$, 
only a $114 \%$ efficiency is observed although the phase is still hexagonal.

\section{Conclusions}

In summary, we have succeeded in preparing efficient quantum cutting $\mathrm{NaGdF}_{4}: \mathrm{Eu}$ nanocrystals useful for energy efficient lighting, using ILs as nanosynthetic templates at room temperature. To the best of our knowledge, it is the simplest method ever reported for the synthesis of rare earth iondoped ternary fluorides which can be scaled up easily. Despite its simplicity in synthesis, very small nanomaterials below $10 \mathrm{~nm}$ in particle size (sometimes $\sim 2 \mathrm{~nm}$ ) are obtained. Analysis suggests that $\left[\mathrm{C}_{2} \mathrm{mim}\right]^{+}$ions anchor to the (110) plane of the primary nuclei, leading to reduced reaction rates and formation of the thermodynamically stable hexagonal polymorph through an imperfect oriented attachment mechanism. However, a less thermodynamically stable cubic polymorph is obtained for ILs with higher alkyl chain lengths such as $\left[\mathrm{C}_{4} \mathrm{mim}\right] \mathrm{Br},\left[\mathrm{C}_{8} \mathrm{mim}\right] \mathrm{Br}$ and $\left[\mathrm{C}_{10} \mathrm{mim}\right] \mathrm{Br}$. As initially extremely small particles with an extraordinarily high surface energy form, the crystal phase completely changes to the hexagonal form spontaneously over an extended time at room temperature. The cubic material obtained is also characterized by a high lattice strain which gets lessened after the phase transition and particle growth. To the best of our knowledge, this kind of spontaneous phase transition at room temperature is not yet documented. Judicious choice of nucleation temperature aside from the ionic liquid is also mandatory, as it not only controls the morphology of the nanoparticles, but also tunes the crystal phase, which is essential for optical property tuning. Only at low temperatures (RT) IL can reveal its true power in directing the phase transition.

\section{Acknowledgements}

The authors would like to acknowledge support from the European Research Council through an ERC Starting grant ("EMIL", contract no. 200475), HASYLAB (project: proposal no. II-20090181) and the DFG cluster of excellence RESOLV. AVM acknowledges the Fonds der ChemischenIndustrie for a Dozentenstipendium, P. G. the Alexander von Humboldt (AvH) Foundation for granting a research fellowship and support from the Department of Science and Technology (Start Up Research Grant for Young Scientist) and UGC Start Up Grant, India. Authors acknowledge Dr P. S. Campbell for his valuable suggestions.

\section{Notes and references}

1 R. T. Wegh, H. Donker, K. D. Oskam and A. Meijerink, Science, 1999, 283, 663-666.

2 J. L. Sommerdijk, A. Bril and A. W. deJager, J. Lumin., 1974, 8, 341-343.
3 P. Ghosh, S. Tang and A.-V. Mudring, J. Mater. Chem., 2011, 21, 8640-8644.

4 G. Chen, T. Y. Ohulchanskyy, S. Liu, W.-C. Law, F. Wu, M. Swihart, H. Ågren and P. N. Prasad, ACS Nano, 2012, 6, 2969-2977.

5 K. A. Abel, J.-C. Boyer and F. C. J. M. Van Veggel, J. Am. Chem. Soc., 2009, 131, 14644-14645.

6 K. W. Krämer, D. Biner, G. Frei, H. U. Güdel, M. P. Hehlen and S. R. Lüthi, Chem. Mater., 2004, 16, 1244-1251.

7 H. Wang and T. Nann, ACS Nano, 2009, 3, 3804-3808.

8 J.-C. Boyer, F. Vetrone, L. A. Cuccia and J. A. Capobianco, J. Am. Chem. Soc., 2006, 128, 7444-7445.

9 A. Mech, M. Karbowiak, L. Kepinski, A. Bednarkiewicz and W. Strek, J. Alloys Compd., 2004, 380, 315-320.

10 P. Ptacek, H. Schäfer, K. Kömpe and M. Haase, Adv. Funct. Mater., 2007, 17, 3843-3848.

11 Y. I. Park, J. H. Kim, K. T. Lee, K.-S. Jeon, H. B. Na, J. H. Yu, H. M. Kim, N. Lee, S. H. Choi, S.-I. Baik, H. Kim, S. P. Park, B.-J. Park, Y. W. Kim, S. H. Lee, S.-Y. Yoon, I. C. Song, W. K. Moon, Y. D. Suh and T. Hyeon, Adv. Mater., 2009, 21, 4467-4471.

12 F. Wang, Y. Han, C. S. Lim, Y. Lu, J. Wang, J. Xu, H. Chen, C. Zhang, M. Hong and X. Liu, Nature, 2010, 463, 10611065.

13 D. Chen, P. Huang, Y. Yu, F. Huang, A. Yang and Y. Wang, Chem. Commun., 2011, 47, 5801-5803.

14 Q. Zhang and Y. Bing, Chem. Commun., 2011, 47, 58675869.

15 Z.-L. Wang, J. H. Hao and H. L. W. Chan, J. Mater. Chem., 2010, 20, 3178-3185.

16 Y. Liu, D. Tu, H. Zhu, R. Li, W. Luo and X. Chen, Adv. Mater., 2010, 22, 3266-3271.

17 H.-X. Mai, Y.-W. Zhang, R. Si, Z.-G. Yan, L.-D. Sun, L.-P. You and C.-H. Yan, J. Am. Chem. Soc., 2006, 128, 6426-6436.

18 L. Wang, R. Yan, Z. Huo, L. Wang, J. Zeng, J. Bao, X. Wang, Q. Peng and Y. Li, Angew. Chem., Int. Ed., 2005, 44, 60546057.

19 A. Kar and A. Patra, Nanoscale, 2012, 4, 3608-3619.

20 M. He, P. Huang, C. Zhang, H. Hu, C. Bao, G. Gao, R. He and D. Cui, Adv. Funct. Mater., 2011, 21, 4470-4477.

21 S. Zeng, G. Ren, C. Xu and Q. Yang, CrystEngComm, 2011, 13, 4276-4281.

22 S. Gai, C. Li, P. Yang and J. Lin, Chem. Rev., 2014, 114, 2343-2389.

23 S. Li, Z. Hou, Z. Cheng, H. Lian, P. Ma, C. Li and J. Lin, RSC Adv., 2013, 3, 5491-5497.

24 N. Niu, F. He, S. Huang, S. Gai, X. Zhang and P. Yang, RSC Adv., 2012, 2, 10337-10344.

25 P. Kannan, F. A. Rahim, R. Chen, X. Teng, L. Huang, H. Sun and D. H. Kim, ACS Appl. Mater. Interfaces, 2013, 5, 3508-3513.

26 M. Ding, C. Lu, Y. Song, Y. Ni and Z. Xu, CrystEngComm, 2014, 16, 1163-1173.

27 Q. Luu, A. Hor, J. Fisher, R. Anderson, S. Liu, T.-S. Luk, H. P. Paudel, M. F. Baroughi, P. S. May and S. Smith, J. Phys. Chem. C, 2014, 118, 3251-3257. 
28 C. Lv, W. Di, Z. Liu, K. Zheng and W. Qin, Dalton Trans., 2014, 43, 3681-3690.

29 F. N. Sayed, V. Grover, S. V. Godbole and A. K. Tyagi, RSC Adv., 2012, 2, 1161-1167.

30 P. Rahman and M. Green, Nanoscale, 2009, 1, 214-224.

31 P. S. Campbell, C. Lorbeer, J. Cybinska and A.-V. Mudring, Adv. Funct. Mater., 2013, 23, 2924-2931.

32 K. Richter, A. Birkner and A.-V. Mudring, Angew. Chem., Int. Ed., 2010, 49, 2431-2435.

33 K. Richter, A. Birkner and A.-V. Mudring, Phys. Chem. Chem. Phys., 2011, 13, 7136-7141.

34 A.-V. Mudring and S. Tang, Eur. J. Inorg. Chem., 2010, 25692581.

35 T. Welton, Chem. Rev., 1999, 99, 2071-2084.

36 J. H. Devis Jr., Working salts: syntheses and uses of ionic liquids containing functionalized ions, in Ionic Liquids Industrial Application for the Green Chemistry, ACS Symp. Ser. 818 , ed. R. D. Rogers and K. R. Seddon, 2002, pp. 247-258.

37 A. Bösmann, G. Francio, E. Janssen, M. Solinas, W. Leitner and P. Wasserscheid, Angew. Chem., Int. Ed., 2001, 40, 2697-2699.

38 J. S. Wilkes, J. Mol. Catal. A: Chem., 2004, 214, 11-17.

39 K. N. Marsh, J. A. Boxall and R. Lichtenthaler, Fluid Phase Equilib., 2004, 219, 93-98.

40 J. Dupont, Acc. Chem. Res., 2011, 44, 1223-1231.

41 Y. Wang and H. Yang, J. Am. Chem. Soc., 2005, 127, 53165317.

42 H. Itoh, K. Naka and Y. Chujo, J. Am. Chem. Soc., 2004, 126, 3026-3027.

43 G. Bühler and C. Feldmann, Angew. Chem., Int. Ed., 2006, 45, 4864-4867.

44 Y. M. Song, M. Yoon, S. Y. Jang, M. D. Jang, Y. J. Cho, C. H. Kim, J. Park and E. H. Cha, J. Phys. Chem. C, 2011, 115, 15311-15317.

45 Y. Zhou and M. Antonietti, J. Am. Chem. Soc., 2003, 125, 14960-14961.

46 W. Zheng, X. Liu, Z. Yan and L. Zhu, ACS Nano, 2009, 3, 115-122.
47 L. Wang, L. Chang, B. Zhao, Z. Yuan, G. Shao and W. Zheng, Inorg. Chem., 2008, 47, 1443-1452.

48 B. G. Trewyn, C. M. Whitman and V. S.-Y. Lin, Nano Lett., 2004, 4, 2139-2143.

49 Y.-J. Zhu, W.-W. Wang, R.-J. Qi and X.-L. Hu, Angew. Chem., Int. Ed., 2004, 43, 1410-1414.

50 J. Jiang, S.-H. Yu, W.-T. Yao, H. Ge and G.-Z. Zhang, Chem. Mater., 2005, 17, 6094-6100.

51 C. Zhang and J. Chen, Chem. Commun., 2010, 46, 592594.

52 X. Liu, J. Zhao, Y. Sun, K. Song, Y. Yu, C. Du, X. Kong and H. Zhang, Chem. Commun., 2009, 6628-6630.

53 T. Nakashima and N. Kimizuka, J. Am. Chem. Soc., 2003, 125, 6386-6387.

54 D. S. Jacob, L. Bitton, J. Grinblat, I. Felner, Y. Koltypin and A. Gedanken, Chem. Mater., 2006, 18, 3162-3168.

55 T. Alammar and A.-V. Mudring, ChemSusChem, 2011, 4, 1796-1804.

56 T. Alammar, H. Noei, Y. Wang and A.-V. Mudring, Nanoscale, 2013, 5, 8045-8055.

57 C. Lorbeer, J. Cybinska and A.-V. Mudring, Chem. Commun., 2010, 46, 571-573.

58 P. T. Anastas and J. C. Warner, Green Chemistry: Theory and Practice, Oxford University Press, New York, 1998.

59 H. Zhang and L. Banfield, J. Phys. Chem. B, 2000, 104, 3481-3487.

60 P. Ghosh and A. Patra, J. Phys. Chem. C, 2007, 111, 7004-7010.

61 D. Wang, L. Liu, F. Zhang, K. Tao, E. Pippe and K. Domen, Nano Lett., 2011, 11, 3649-3655.

62 B. J. Rivest, K.-L. Fong, K. P. Jain, F. M. Toney and P. A. Alivisatos, J. Phys. Chem. Lett., 2011, 2, 24022406.

63 G. Zimmerer, Radiat. Meas., 2007, 42, 859-864.

64 G. K. Williamson and W. H. Hall, Acta. Metall., 1953, 1, 22-31.

65 R. L. Penn and J. F. Banfield, Science, 1998, 281, 969971.

66 B. R. Judd, Phy. Rev., 1962, 127, 750-761.

67 G. S. Ofelt, J. Chem. Phys., 1962, 37, 511. 